\title{
Frequency of Hypoglycemia in Medical Emergency Department of A Tertiary Care Hospital of Bangladesh
}

Shangkar Barua ${ }^{1 *}$

Mohammad Mahabubul Alam Chowdhury ${ }^{2}$ Ahmed Salam ${ }^{3}$

Md. Rafiq Uddin ${ }^{4}$

Sumon Rahman Chowdhury ${ }^{5}$

Mohammad Mahmudul Kabir 6

Md. Lutful Kabir ${ }^{7}$

Sharmin Chowdhury ${ }^{8}$

S. M. Mohiuddin 9

'Department of Endocrinology \& Metabolism Cox's Bazar Medical College

Cox's Bazar, Bangladesh.

${ }^{2}$ Department of Otolaryngology and Head \& Neck Surgery Institute of Applied Health Sciences (IAHS) Chattogram, Bangladesh.

${ }^{3}$ Department of Endocrinology \& Metabolism BIHS General Hospital

Dhaka, Bangladesh.

${ }^{4}$ Department of Endocrinology

Chittagong Medical College

Chattogram, Bangladesh.

${ }^{5}$ Department of Diabetes, Endocrinology \& Metabolism Chattogram Diabetic General Hospital

Chattogram, Bangladesh.

${ }^{6}$ Upazila Health Complex

Meghna, Comilla, Bangladesh.

${ }^{7}$ Department of Endocrinology

Rangpur Medical College, Rangpur, Bangladesh.

${ }^{8}$ Department of Endocrinology

National Institute of Neurosciences and Hospital Dhaka, Bangladesh

${ }^{9}$ Department of Endocrinology \& Metabolism Sir Salimullah Medical College

Dhaka, Bangladesh.

\section{${ }^{*}$ Correspondence to:}

Dr. Shangkar Barua

Assistant Professor

Department of Endocrinology \& Metabolism

Cox's Bazar Medical College

Cox's Bazar, Bangladesh.

Mobile : +8801824 444481

Email : baruashankar690@gmail.com

Date of Submission : 25.07 .2020

Date of Acceptance : $\quad 24.12 .2020$

www.banglajol.info/index.php/CMOSHMCJ

\begin{abstract}
Background: Hypoglycemia is the commonest medical emergency in diabetic patients. It is also the most important limiting factor in intensive control of diabetes. To find out the frequency of hypoglycemia in Medical Emergency of BIRDEM General Hospital.
\end{abstract}

Materials and methods: This cross sectional observational study was done at the Medical Emergency Department of BIRDEM General Hospital, Dhaka, during the period of March, 2015 to November, 2015. Among the patients attending the emergency department, hypoglycemic patients were identified. Socio-demographic, clinical and biochemical data was collected from these patients. Statistical analysis was done with SPSS version 23.0 .

Results: Among the 20564 patients attending the medical emergency department in the specified time period, 577 (2.8\%) patients had hypoglycemia. More than half (50.09\%) patients were found mild impairment of consciousness (GCS >12).

Conclusion: The present study found that frequency of hypoglycemia in patients attending in Medical Emergency Department of BIRDEM General Hospital was $2.80 \%$.

Key words : Hypoglycemia; Diabetes; Mellitus; BIRDEM.

\section{INTRODUCTION}

Diabetes mellitus contributes greatly to the global health burden of this century. The prevalence of Type 2 Diabetes Mellitus (T2DM) has been escalating in the developing countries ${ }^{1}$. Hypoglycemia is the most common endocrine emergency faced by physicians. Hypoglycemia is defined as a measurable glucose concentration, 70 $\mathrm{mg} / \mathrm{dL}(3.9 \mathrm{mmol} / \mathrm{L})^{2}$. ADA and European Association for the Study of Diabetes (EASD) guidelines recommend hypoglycemia risk to be considered while treating T2DM patients ${ }^{3}$. It is established that the primary cause of hypoglycemia among T2DM patients is medications, namely sulfonylureas and insulin in $90 \%$ of the diabetic patients ${ }^{4-6}$. However, hypoglycemia may occur due to other causes apart from medications, which needs to be explored. Patient's well-being can get affected directly due to hypoglycemic symptoms and indirectly due to fear of subsequent hypoglycemic episodes ${ }^{7}$. Even mild symptoms of hypoglycemia can affect the treatment of T2DM if patient's fear of hypoglycemia overtakes the willingness to take medications $^{6}$. Recurrent hypoglycemic episodes can lead to poor quality of life, ${ }^{7}$ increased anxiety, depression, and mood swings ${ }^{7,8}$.

\section{MATERIALS AND METHODS}

Observational Cross-sectional study was carried out in the Medical Emergency Department of BIRDEM General Hospital, Dhaka during March 2015 to November 2015. All Patients attending Medical Emergency Department of BIRDEM General Hospital were included in this study and Diabetic patients who are not willing to participate were excluded in this study. Data were collected from hypoglycemic patient 
(After recovery) attendants and previous records. Data were collected with a pre-tested structured questionnaire containing history, clinical examinations and capillary blood glucose test by glucometer. In Emergency Department, a detailed history of the illness was taken from the patients / patients' attendant. The researcher himself carried out through general examinations and recorded the findings. The data was collected and edited manually. Then it was entered into SPSS version 23, computer software program. The tests statistics used to analyze the data were descriptive statistics. The data presented on categorical scale were expressed as frequency and corresponding percentage, while the quantitative data were presented as mean and Standard Deviation $( \pm \mathrm{SD})$. For all analyses level of significance was set at 0.05 and $p$-value $<0.05$ was considered significant.

\section{RESULTS}

Total number of attended patients in medical emergency department during study period were 20564, among them 577(2.80\%) patients had hypoglycemia. Out of 577 hypoglycemic patients $215(37.26 \%)$ were admitted and 362(62.74\%) were non admitted patients. Frequency of hypoglycemia was $2.80 \%$ (Table-I). Mean age was found 56.1 \pm 9.9 years. Maximum (69.15\%) hypoglycemic patients belonged to age $>50$ age, $319(55.28 \%)$ were male, 312(40.55\%) were unemployed, 160(27.73\%) patients completed $\geq \mathrm{HSC}$ education and 304(52.69\%) were BMI $23.0-24.9 \mathrm{~kg} / \mathrm{m}^{2}$ (Table-II). More than one third (36.22\%) patients were duration of diabetes 11-20 years (Table-III). Majority $(85.62 \%)$ patients were found HbA1c $\geq 7.0$ percent (TableIV). Majority (44.54\%) patients had CKD followed by 106(18.37\%) had AKI, 98(16.98\%) had UTI, 38(6.58\%) had CLD, 28(4.85\%) had IHD, 25(4.33\%) had aspiration pneumonia and $19(3.29 \%)$ had electrolyte imbalance (Table-V). Requirement of Intravenous (IV) glucose was found 224(38.82\%) and $439(76.08 \%)$ patients received oral anti diabetic medication (Table-VI). More than three fourth $(36.57 \%)$ patients were found $\mathrm{CBG}>3.0 \mathrm{mmol} / \mathrm{L}$ (Table-VII). More than half (50.09\%) patients were found mild impairment of consciousness (GCS $>12$ ) (Table-VIII).

Table I : Frequency of hypoglycemia among patients attended in Medical Emergency Department of BIRDEM General Hospital $(n=20564)$.

\begin{tabular}{lcc} 
& Frequency & Percentage \\
$\begin{array}{lcc}\text { Number of patients attending in } \\
\text { medical emergency department }\end{array}$ & 20564 & 100.0 \\
$\begin{array}{l}\text { Total number of hypoglycemia } \\
\text { Number of patients requiring }\end{array}$ & 577 & 2.80 \\
$\begin{array}{l}\text { admission } \\
\begin{array}{l}\text { Number of patient not requiring } \\
\text { admission }\end{array}\end{array}$ & 215 & 37.26 \\
\hline
\end{tabular}

Table II : Demographic characteristics of the hypoglycemic patients $(\mathrm{n}=577)$

\begin{tabular}{lrr} 
Age (Years) & Frequency & Percentage \\
$30-40$ & & \\
$41-50$ & 68 & 11.79 \\
$51-60$ & 110 & 19.06 \\
$61-70$ & 241 & 41.77 \\
$>70$ & 109 & 18.89 \\
Mean \pm SD & 49 & 8.49 \\
Sex & 56.1 & \pm 9.9 \\
Male & & \\
Female & 319 & 55.29 \\
Occupational status & 258 & 44.71 \\
Govt. employee & & \\
Non Govt. employee & 50 & 8.67 \\
Self employed & 69 & 11.96 \\
Unemployed & 135 & 23.40 \\
Other & 312 & 54.07 \\
Educational status & 11 & 1.91 \\
$\quad<$ HSC & & \\
$\quad \geq$ HSC & 417 & 72.27 \\
BMI (kg/m ${ }^{2}$ r & 160 & 27.73 \\
$<18$ & & \\
18.0-22.9 & 54 & 9.36 \\
$23.0-24.9$ & 197 & 34.14 \\
$\geq 25.0$ & 304 & 52.69 \\
\hline
\end{tabular}

Table III : Duration of diabetes of the hypoglycemic patients $(n=577)$.

Duration of diabetes (years) Frequency Percentage

\begin{tabular}{lrr}
$<5$ & 186 & 32.24 \\
$5-10$ & 158 & 27.38 \\
$11-20$ & 209 & 36.22 \\
$>20$ & 24 & 4.16 \\
\hline
\end{tabular}

Table IV : Glycemic status of the hypoglycemic patients $(\mathrm{n}=577)$.

\begin{tabular}{lcc} 
HbA1c (\%) & Frequency & Percentage \\
$<7.0$ & 83 & 14.38 \\
$\geq 7.0$ & 494 & 85.62 \\
\hline
\end{tabular}

Table V : Associated illness of the hypoglycemic patients ( $\mathrm{n}=577$ ).

\begin{tabular}{lrc} 
& Frequency & Percentage \\
CKD & 257 & 44.54 \\
AKI & 106 & 18.37 \\
UTI & 98 & 16.98 \\
CLD & 38 & 6.58 \\
IHD & 28 & 4.85 \\
Aspiration pneumonia & 25 & 4.33 \\
Electrolyte imbalance & 19 & 3.29 \\
Acute gastroenteritis & 17 & 2.95 \\
Pneumonia & 13 & 2.25 \\
Arrhythmia & 13 & 2.25 \\
Stroke & 10 & 1.73 \\
Heart failure & 10 & 1.73 \\
Respiratory failure & 4 & 0.69 \\
\hline
\end{tabular}


Table VI : Treatment modalities of the hypoglycemic patients $(\mathrm{n}=577)$

\begin{tabular}{lrc} 
& Frequency & Percentage \\
Treatment modalities & & \\
IV glucose & 224 & 38.82 \\
Oral glucose & 353 & 61.18 \\
Anti diabetic medication & & \\
Insulin & 96 & 16.64 \\
Oral & 439 & 76.08 \\
Oral + Insulin & 42 & 7.28 \\
\hline
\end{tabular}

Table VII : CBG of the hypoglycemic patients ( $\mathrm{n}=577)$.

\begin{tabular}{lcc} 
CBG & Frequency & Percentage \\
$1 \mathrm{mmol} / \mathrm{L}$ & 13 & 2.25 \\
$1.1-2.0 \mathrm{mmol} / \mathrm{L}$ & 156 & 27.04 \\
$2.1-3.0 \mathrm{mmol} / \mathrm{L}$ & 197 & 34.14 \\
$>3.0 \mathrm{mmol} / \mathrm{L}$ & 211 & 36.57 \\
\hline
\end{tabular}

Table VIII : Glasgow coma scale of the hypoglycemic patients $(\mathrm{n}=577)$.

\begin{tabular}{lcc} 
GCS & Frequency & Percentage \\
Severe $(<9)$ & 91 & 15.77 \\
Moderate $(9-12)$ & 197 & 34.14 \\
Mild $(>12)$ & 289 & 50.09 \\
\hline
\end{tabular}

\section{DISCUSSION}

In present study observed that total number of attended patients in medical emergency department during study period were 20564, among them $577(2.80 \%)$ patients had hypoglycemia. Out of 577 hypoglycemic patients $215(37.26 \%$ ) were admitted and $362(62.74 \%)$ were non admitted patients. Frequency of hypoglycemia was $2.80 \%$. Many studies were found approximately similar to our study, they showed incidence of hypoglycemia were $5.1 \%, 6.8 \%, 9.8 \%$, but different results are found in some western studies like $18.7 \%$ and $17 \%{ }^{9-13}$. Jimenez-Montero et al also reported 55620 patients were attended at the Emergency Department. Of them, 4434 had non-communicable conditions including 961 diabetics which was $1.72 \%{ }^{14}$.

In current study observed that the mean age was found $56.1 \pm 9.9$ years. Maximum (69.15\%) hypoglycemic patients belonged to age $>50$ age, $319(55.28 \%$ ) were male, $312(40.55 \%)$ were unemployed, 160(27.73\%) patients completed HSC education and 304(52.69\%) were BMI 23.0-24.9 kg/m². Shih et al observed that mean age of patients was 66.3 years ${ }^{15}$. Gautam et al in their study found that majority $(87.7 \%)$ of the respondents with hypoglycemia were above 40 years of age ${ }^{16}$. Hsiao and Chien reported that $50 \%$ patients were male another study Shih et al found $47.3 \%$ male patients with hypoglycemia ${ }^{17,15}$. Tsai et al in their study found that the mean BMI of severe hypoglycemic patients was $23.8 \pm 4.0 \mathrm{~kg} / \mathrm{m}^{2}$ with $28.8 \%$ in the overweight category $^{18}$. Su and Liao study reported total of 186 cases of hypoglycemia aged from 26 to 98 years old with an average age of $70.5 \pm 15.3$ years. Kumar et al also observed $751(62.8 \%)$ were males and 445 (37.2\%) were females. Mean age distribution was $57 \pm 14.7$ years; the youngest being 16 years old and the oldest 98 years of age ${ }^{19-20}$.

In present study observed more than one third (36.22\%) patients had duration of diabetes 11-20 years. Lin et al found that patients with non-recurrent hypoglycemia had duration of diabetes $12.41 \pm 8.07$ years and recurrent hypoglycemia had duration $15.35 \pm 8.29$ years $^{21}$.

In this study observed that the majority $(85.62 \%)$ patients were found $\mathrm{HbA1c} 7.0$ percent. Hsiao and Chien found the risk increased as the HbAlc level approached the American Diabetes Association goal of less than $7.0 \%{ }^{17}$. The patients who have a lower HbA1c level should be encouraged to be more diligent about meal planning, flexible insulin and other drug regimens and frequent self-monitor blood sugar.

In present study showed the majority (44.54\%) patients had CKD followed by $106(18.37 \%)$ had AKI, 98(16.98\%) had UTI, $38(6.58 \%)$ had CLD, 28(4.85\%) had IHD, 25(4.33\%) had aspiration pneumonia and $19(3.29 \%)$ had electrolyte imbalance. $\mathrm{Su}$ and Liao study reported concomitant infection (55.4\%) was more commonly observed than the lack of a recent meal (44.6\%). UTI $(33.3 \%)$ was more commonly observed than pneumonia $(23.1 \%)$ and BTI $(2.7 \%)^{19}$. Kumar et al also reported similar observation they showed CKD 61 (11.4\%), acute/chronic liver dysfunction 13 (2.43\%), malignancies 10 (1.87\%) drugs/toxins $3(0.56 \%)$, other factors $13(2.43 \%)$ and unknown $7(1.31 \%)^{20}$.

In this study observed requirement of IV glucose was found $224(38.82 \%)$ and $439(76.08 \%)$ patients received oral anti diabetic medication. Lin et al in their study found that of the patients of hypoglycemia, Insulin was used by 46(28.9\%) patients, Oral anti-diabetic agents by $116(73.0 \%)$ Sulfonylurea 51(32.1\%) Meglitinde 53(33.3\%) Metformin 60(37.7\%) Thiazolidinediones $8(5.0 \%)$ Polypharmacy $71(44.7 \%)^{21}$. Kumar et al reported underlying causes for hypoglycemia in diabetic group included intensive control of blood sugars by oral hypoglycemic agents (OHAs) 204(38.13\%), intensive control of blood sugars by insulin 103(19.25\%), intensive control of blood sugars by with both insulin and OHAs $13(2.43 \%)^{20}$.

In this study showed more than half $(50.09 \%)$ patients were found mild impairment of consciousness (GCS $>12$ ). Tsai et al which is consistent with our study showed that risk factor responsible for hypoglycemia were meal related $(p<0.001)$, renal impairment $(\mathrm{p}<0.001)$, infection $(\mathrm{p}<0.001)^{18}$. 


\section{CONCLUSION}

The present study found that frequency of hypoglycemia in patients attending in Medical Emergency Department of BIRDEM General Hospital was $2.80 \%$. Major factors associated with not requiring hospital admission were younger age, less duration of $\mathrm{DM}$, treatment with $\mathrm{OAD}$, correction of hypoglycemia by oral glucose, high GCS and higher mean blood glucose at presentation than admitted patients.

\section{DISCLOSURE}

All the authors declared no competing interest.

\section{REFERENCES}

1. Samya V, Shriraam V, Jasmine A, Akila GV, Anitha Rani M, Durai V et al. Prevalence of Hypoglycemia Among Patients With Type 2 Diabetes Mellitus in a Rural Health Center in South India. Journal of Primary Care \& Community Health. 2019;10: 1-7.

2. American Diabetes Association. 6. Glycemic targets: Standards of Medical Care in Diabetesd. Diabetes Care. 2020; 43(Suppl. 1):S66-S76.

3. Inzucchi SE, Bergenstal RM, Buse JB, Diamant M, Ferranninini E, Nauck M et al. Management of hyperglycaemia in type 2 diabetes: a patient-centered approach. Position statement of the American Diabetes Association (ADA) and the European Association for the Study of Diabetes (EASD). Diabetes care. 2012;35:1364-1379.

4. Nathan DM, Buse JB, Davidson MB, Ferranninini E, Holman RR, Sherwin R, et al. Medical management of hyperglycemia in type 2 diabetes: A consensus algorithm for the initiation and adjustment of therapy: A consensus statement of the American Diabetes Association and the European Association for the Study of Diabetes. Diabetes Care. 2009;32:193-203.

5. Agarwal AA, Jadhav PR, Deshmukh YA. Prescribing pattern and efficacy of anti-diabetic drugs in maintaining optimal glycemic levels in diabetic patients. J Basic Clin Pharm. 2014;5:79-83.

6. Amiel SA, Dixon T, Mann R, Jameson K. Hypoglycaemia in type 2 diabetes. Diabet Med. 2008;25:245-254.

7. Lundkvist J, Berne C, Bolinder B, Jonsson L. The economic and quality of life impact of hypoglycemia. Eur J Health Econ. 2005;6:197-202.

8. Wredling RA, Theorell PG, Roll HM, Lins PE, Adamson UK. Psychosocial state of patients with IDDM prone to recurrent episodes of severe hypoglycemia. Diabetes Care. 1992;15:518-521.

9. Van den Berghe G, Wouters P, Weekers F, Verwaest C, Bruyninckx F, Schetz M. Intensive insulin therapy in the critically ill patients. N Engl J Med. 2001;345(19):1359-1367.

10. Finfer S, Chittock DR, Su SY, Blair D, Foster D, Dhingra V. Intensive versus conventional glucose control in critically ill patients. N Engl J Med. 2009;360(13):1283-9127.

11. Preiser JC, Devos P, Ruiz-Santana S, Melot C, Annane D, Groeneveld J. A prospective randomised multi-centre controlled trial on tight glucose control by intensive insulin therapy in adult intensive care units: the Glucontrol study. Intensive Care Med. 2009;35(10):1738-1748.

12. Brunkhorst FM, Engel C, Bloos F, Meier-Hellmann A, Ragaller M, Weiler N et al. German Competence Network Sepsis (SepNet). Intensive insulin therapy and pentastarch resuscitation in severe sepsis. N Engl J Med. 2008;358(2):125-139.

13. Van den Berghe G, Wilmer A, Hermans G, Meersseman W, Wouters PJ, Milants I. Intensive insulin therapy in the medical ICU. N Engl J Med. 2006;354(5): 449-461.

14. Jimenez-Montero JG, Hernandez-Saborío I, Cob-Sanchez A. Severe Hypoglycemia in an Emergency Department of a General Hospital in Costa Rica. Diabetes Complications. 2019; 3(2): 1-5.

15. Shih IM, Mazur MT, Kurman RJ. Gestational Trophoblastic Disease. Sternberg's Diagnostic Surgical Pathology: Sixth Edition. Wolters Kluwer Health Adis (ESP). 2015.

16. Gautam A, Bhatta DN, Aryal UR. Diabetes related health knowledge, attitude and practice among diabetic patients in Nepal, BMC Endocrine Disorders. 2015;15(25): 2-8.

17. Hsiao YC, Chien MN. Severe Hypoglycemia in Type 2 Diabetes: A Hospital-based Retrospective Study. J Intern Med Taiwan. 2006;17:73-77.

18. Tsai TC, Lee CH, Cheng BC, Kung CT, Chen FC, Shen FC. Body Mass Index-Mortality Relationship in Severe Hypoglycemic Patients with Type 2 Diabetes. The American Journal of the Medical Sciences. 2015;349(3):192-198.

19. Su YJ, Liao CJ. Hypoglycemia in Emergency Department. Journal of Acute Disease. 2015; 59-62.

20. Kumar JG, Abhilash KPP, Saya RP, Tadipaneni N, Bose JM. A retrospective study on epidemiology of hypoglycemia in Emergency Department. Indian J Endocrinol Metab. 2017; 21(1): 119-124.

21. Lin Y, Hsu C, Sheu WH, Chu S, Wu C, Tsai S. Risk Factors for Recurrent Hypoglycemia in Hospitalized Diabetic Patients Admitted for Severe Hypoglycemia, Yonsei Med J. 2010;51(3): 367-374. 